\title{
Evaluation of the Interaction Among Microalgae Spirulina sp, Plastics Polyethylene Terephthalate and Polypropylene in Freshwater Environment
}

\author{
Adian Khoironi ${ }^{1 *}$, Sutrisno Anggoro ${ }^{1,2}$, Sudarno ${ }^{1,3}$ \\ 1 Doctoral Program Environmental Sciences of Diponegoro University, Semarang, Indonesia \\ 2 Faculty of Fisheries and Marine Science of Diponegoro University, Semarang, Indonesia \\ 3 Environmental Engineering Department of Diponegoro University, Semarang, Indonesia \\ * Corresponding author's e-mail: batik.ayacantik@gmail.com
}

\begin{abstract}
The annual plastic production in Indonesia has exceeded 4.6 million tons and accumulated in the aquatic system. Polyethylene terephthalate (PET) and Polypropylene (PP) are the most widely used plastics in manufacture of packaging, fibres, and drinking bottles, etc. The degradation of these plastics to micro sizes leads to environmental threats, especially when the micro plastics interact with fresh water microorganism such as microalgae. Therefore, the study on the interaction between micro plastics and microorganisms is really important. The aim of this study was to evaluate the impact of microplastics on the growth of microalgae Spirulina sp and also to evaluate the contribution of microalgae Spirulina $s p$ to the plastic degradation. The interaction between microalgae and microplastics was evaluated in a $1 \mathrm{~L}$ glass bioreactor contained microalgae Spirulina sp and PP and PET microplastics with the size of $1 \mathrm{~mm}$ at various concentrations $(150 \mathrm{mg} / 500 \mathrm{~mL}, 250 / 500 \mathrm{~mL}$ and $275 \mathrm{mg} / 500 \mathrm{~mL})$ for 112 days. The results showed that the tensile strength of micro plastic PET decreased by $0.9939 \mathrm{MPa} /$ day while PP decreased by $0.1977 \mathrm{MPa}$ /day. The EDX analysis of microplastics showed that the decreasing carbon in PET (48.61\%) was higher as compared to PP (36.7\%). FTIR analysis of Spirulina sp cells showed that the $\mathrm{CO}_{2}$ evolution of cells imposed by PET microplastic was higher than imposed by PP. The growth rate of Spirulina sp applied by micro plastic was lower than the control and the increase of microplastic concentration significantly reduced the growth rate of algae by $75 \%$. This research concluded that biodegradation has important role in the degradation process of plastic.
\end{abstract}

Keywords: plastic, polypropylene, polyethylene terephthalate, Sprirulina $s p$

\section{INTRODUCTION}

Indonesia is facing plastic waste threats which currently reach 2.4 million tonnes and spread to aquatic environments. These plastics contaminate the natural environment and also endanger the ecosystem, especially when they degrade into small pieces (Moore, 2008). The plastic debris in the environment includes ropes, plastic bag or packaging, whichj are available in the form of macroplastics and microplastics. Large plastic items (macroplastics) have been indicated in the marine system for long time period (Derraik, 2002). Microplastics ( $<5 \mathrm{~mm}$ ) have recently attracted attention because of their ingestbility by organisms as well as transport for the pollutants into food chain (Teuten et al., 2009). Microplastics in the aquatic environment that can originate from various sources such as UV degradation and fragmentation of plastics or caused by damage during the transportation process, mechanical damage and also aquatic environment direct release (Andrady, 2003; Cole et al., 2011; Erikson et al., 2013; Rezania et al., 2018).

The most common and abundant polymers are high-density polyethylene (HDPE), lowdensity polyethylene (LDPE), polyvinyl chloride (PVC), polystyrene (PS), polypropylene (PP) and 
polyethylene terephthalate (PET), and among these plastic, PET and PP are the major plastic wastes which have different chemical-physical properties and functions (Andrady and Neal, 2009). PET and PP are derived from thermoplastic polymers which are mostly used for packaging materials. For example, single use plastic bottles for mineral water and soft drinks are made from polyethylene terephthalate (PET) which is highly recyclable with a density of $1.41 \mathrm{~g} / \mathrm{cm}^{3}$ (Mortula, 2013). Furthermore, PET contains two hydroxyl $(\mathrm{OH})$ groups and dicarboxylic aromatic acid, which comprises a large, six-sided carbon (or aromatic) ring and two carboxyl $\left(\mathrm{CO}_{2} \mathrm{H}\right)$ groups. Under heat and catalysts, the hydroxyl and carboxyl groups will react to form ester (CO-O) (Venkatachalam et al., 2012; Farzi et al., 2019). The presence of a large aromatic ring in PET makes it stiff, strong, tough, hydrolytic, solvent resistant (Venkatachalam et al., 2012) and hygroscopic (Ma and Buhshan, 2003; CWC Best Practices in PET Recycling, 1997). In turn, polypropylene is polyolefin with linear hydrocarbon polymers (Arutchelvi, 2008) has the lowest density among commodity plastics that is about 0.94 $\mathrm{g} / \mathrm{cm}^{3}$ (Howe, 1999; Cole, 2002 and Schimanski, 2018). PP has three stereo configurations that can be distinguished, namely the isotactic, the syndiotactic and the atactic form. The isotactic PP (i-PP) contributes the most to the consumption of polypropylene because of its properties: ease to handle, stablility in aqueous solutions and organic solvents and also thermal-stability (Schimanski, 2018; Bertin et al., 2010). PP also has an excellent property regarding on chemical and temperature resistance which makes PP particularly suitable for application in many food packaging purposes especially that have to be sterilized frequently (Maddah, 2016).

The degradation process is the most important fate of plastics in the environment. Degradation of plastics may occur through some mechanisms that involve thermal, chemical, photo and biological degradation (Alshehrei, 2017; Gewert et al., 2015). Biodegradation of plastics occurs due to the action of extra cellular enzymes secreted by the microorganisms when the organisms attach to the surface of plastics leading to physical and chemical change of the latter (Lucas et al., 2008; Alshehrei, 2017; Arutchelvi et al., 2008). The growth of microorganisms utilising the plastics polymer as a carbon source and with the availability of oxygen, plastics will degrade completely by using $\mathrm{CO}_{2}$ and the biomass as an ultimate product (Shah et al., 2008; Muthukumar and Veerappapillai, 2015; Arutchelvi et al., 2008; Arkatkar et al., 2009).

The hydrophilicity of plastic has important role in attaching microorganism cell to the plastic surface and therefore will affect the biodegradation process of plastic. $\mathrm{PP}$ which has a $\mathrm{CH}_{2}$ group will be prone to attaching to hydrophobic polymeric surfaces (Arutchelvi et al., 2008). Due to the presence of ester and terephthalate group in PET, this plastic it polar molecule and therefore it is more hydrophilic (Venkatachalam et al., 2012). On other hand, Lucas et al. (2008) assumed that the esters group in PET makes it more resistant to biodegradation compared to other polymers. The extracellular polymeric substances produced by microorganisms can play a role as surfactants contain both hydrophobic and hydrophilic groups that support the exchanges between hydrophilic and hydrophobic phases (Lucas et al., 2008).

Microalgae are photosynthetic microorganisms which utilize $\mathrm{CO}_{2}$ as carbon source to form biomass. Microalgae are mostly used as food sources in which they contain hydrocarbon, lipids and protein and other high added value compounds (Habib, 2008 and Hariyati, 2008). Since they are used for food products, microalgae must be free from pollutants, including microplastics. Plastic can be used as carbon sources for microalgae and the release of plastic additives promote the growth of microorganisms by supplying the nutrient source (Rummel et al., 2017). Since micro-plastics have sizes of 1 to $5 \mathrm{~mm}$ (Lee et al. 2013), they are a suitable medium for bacteria and microalgae to form a bio-fouling. Bio-fouling that occurs on micro plastic surfaces causes shading effects which decrease light intensity, thus affecting the photosynthesis of microalgae (Sjollema et al., 2015; Yurtsever et al., 2017). Furthermore, the impact of micro plastics on microalgae growth is also affected by the availability of oxygen and $\mathrm{CO}_{2}$ evolution as the consequence of plastic degradation (Shah et al., 2008; Arutchelvi et al., 2008).

The study on the biodegradation of PET and PP carried out simultaneously has not been found by the authors but some reports about PET and PP biodegradation in separate experiment have been observed. Farzi et al., (2019) studied the kinetic modelling in the process polyethylene terephthalate biodegradation waste using Streptomyces $s p$. The results showed that particle 
sizes and time of reaction were the most important parameters affecting biodegradation and the Michaelis-menten model can predict precisely the experimental results. Auta et al. (2018) evaluated the growth kinetics and biodeterioration of polyethylene microplastics by Bacillus $s p$ and Rhodococcus $s p$ and concluded that these microorganisms could modify and utilize PP microplastics as carbon source.

Lagarde et al. (2016) investigated the effect of polymer type during the interaction between micro plastic and freshwater microalgae. They reported that microalgae were over-expressed of sugar biosynthesis in HDPE rather than in PP. Furthermore, Yoshida et al., (2016) isolated a bacterium to breakdown the PET within 6 weeks. Long et al. (2015) evaluated the interaction between microplastics and phytoplankton aggregates. The result showed that marine aggregates can be an efficient sink for the microplastics.

Sharon and Sharon (2012) studied the plastic biodegradation of polyethylene terephthalate plastic in microbial culture and the degradation was slow and weak. It also demonstrated that microbes could act on the polyethylene terephthalate to form biofouling. Nowak et al. (2011) studied the biodegradation of modified PET by using polyester in Penicillium funiculosum culture. The result showed that modified PET was not significantly degraded in the presence of the culture. Since the interaction of micro plastic and microorganism is relatively strong, further research is required. The purposes of this research were to evaluate the contribution of Spirulina $s p$ in the process of plastic degradation and to observe the impact of microplastics on the Spirulina sp growth.

\section{MATERIALS AND METHODS}

\section{Materials}

Polyethylene Terephthalate (PET) used in this research was obtained from Danone Indonesia that already standardized by SNI 19-4370-2004 (Nasional Indonesian Standart for Plastic bottle Single-use). Polypropylene (PP) $15 \mu \mathrm{m}$ thick was provided by PT. Indofood Sukses Makmur Tbk.

\section{Spirulina sp cultivation}

Spirulina $s p$ used in this experiment was supplied by C-Biore Laboratory, Diponegoro
University. The experiment was started by testing the physiological form of Spirulina sp which included maximum cell density by using a spectrophotometer, measurement of $\mathrm{pH}$, temperature, oxygen content and $\mathrm{CO}_{2}$ content. Furthermore, Spirulina sp is placed in 2 pieces of $35 \mathrm{~cm} \times 25 \mathrm{~cm}$ glass ponds and 7 pieces of $500 \mathrm{~mL}$ Erlenmeyer, each equipped with an aerator as a source of oxygen and LED lights (3000 lux) to provide light intensity, then the temperature is maintained at $24-26^{\circ} \mathrm{C}$ and $\mathrm{pH}$ between 7-8. Nutrition needed to maintain the Spirulina $s p$ growth is given every 2 days with a mix of TSP and Urea $12.5 \mathrm{mg} / 250 \mathrm{~mL}$ of Spirulina $s p$ and $100 \mathrm{mg} \mathrm{NaHCO} / 250 \mathrm{~mL}$ Spirulina sp (Hadiyanto and Azim, 2012).

\section{Sample Preparation}

PET and PP plastics were washed with etanol and dried at room temperature for 24 hours and then the plastic was cut to the size of $5 \times 5 \mathrm{~cm}$ to be applied in a glass ponds containing Spirulina $s p$. Microplastics were obtained by cutting a PET and PP plastic in the same size between 1-2 $\mu \mathrm{m}$. The microplastic was weighted carefully at $150 \mathrm{mg}$, $200 \mathrm{mg}$ and $275 \mathrm{mg}$ and mixed into $500 \mathrm{~mL}$ of Spirulina sp culture. Stirring was done with the aerators so that microplastics were distributed into the Spirulina $s p$ culture properly. Nutrient, $\mathrm{pH}$, temperature, light intensity and oxygen supply were maintained and the growth was measured by using a spectrophotometer (Spectroquant pharo $300 \mathrm{M}$ and Spectrophotometer SP -300 Optima) at $560 \mathrm{~nm}$ wavelength and ultrapure water was used as a blank solution (Hadiyanto et al., 2012).

\section{Tensile strength measurement}

In SNI 7818: 2014 and SNI 7188.7.2011, it was stated that one of the degradability tests for plastic is by using tensile strength test and it was also supported by ISO 527-3 (Lucas et al., 2008, Alvarez-zeferino et al., 2015, Guo Meng et al., 2016, Hoffmann et al., 1994, Hongliang et al., 2017, Strapasson et al., 2005). Tensile strength tests were conducted by tensile meter (Brookfield CT3 -4500) which were carried out on plastic before and after treatment by Spirulina $s p$. The plastics exposed by Spirulina $s p$ treatment were measured every 7 days for 112 days to measure their tensile strength. 


\section{Morphologies}

The morphology of PET and PP was observed using scanning electron microscope (SEM) and combination with Energy Dispersive X-ray spectroscopy (EDX) to determine the inorganic elements contained in the material (Lucas et al., 2008). The analysis was conducted at room temperature and metalized using Au.A Jeol (model JSM- 6510 LA ) at 3000x magnification.

\section{FTIR analysis}

FTIR is a common technique used for the study of macromolecules such as PET and PP polymer that was recommended for investigation of plastic degradation as mentioned in ISO 4582 and ISO 4892 for UV exposure, and for microorganism's surface colonization in ISO 846 and ISO 11266 (Lucas et al., 2008, Melissa et al., 2018, Schmitt et al., 1998). PET and PP plastics that were applied in Spirulina $s p$ were taken every 7 days for about 112 days. Prior to the FTIR test, plastics were rinsed with aquadest and left to dry for 24 hours, then the plastic was cut at a size of $1.5 \times 2 \mathrm{~cm}$. A Perkin Elmer Type Frontier was used to collect spectra from $4000-200 \mathrm{~cm}^{-1}$ (SNI 19-4370-2004 method) and ASTM D628889. FTIR test was also conducted in Spirulina $s p$ which had interacted with microplastic treatment for 7 days. Filter Spirulina $s p$ containing micro plastic with diameter of $200 \mathrm{~mm} / 8$ "stainless steel 40 mesh sifter sieve fine wire strainer to obtain Spirulina $s p$ without microplastic.

\section{RESULT AND DISCUSSION}

\section{Contribution of Spirulina sp in the plastic degradation processes}

The standard test of the elasticity (elongation) properties for degraded plastics in Indonesia is regulated by SNI 7188.7: 2011 (BSN, 2011) which requires tensile elongation, while on an international scale, it is regulated in ASTM D3826 concerning the procedures for determining the end point of degradation in Polyethylene and Polypropylene plastic using tensile test. The quantitative relationship between tensile strength and degradation is the first step in the process of investigating yjr plastic degradation (Guo et al., 2016). When plastic changes both due to biotic and abiotic factors, the strength of stress and the versatility of plastic will alter in line with changes in the molecular structure of the polymer. Therefore, the initial identification of the plastic degradation process is by measuring the tensile strength. There are several factors that influence the tensile strength of plastic, namely the molecular structure that also affects the density of the plastic, the temperature at which the plastic is applied and the chemical composition of the plastic itself. Measurements of tensile strength were carried out on two types of plastic and the measurement results can be shown in the curve of tensile strength degradation over time.

\section{The change in mechanical polymer property by tensile strength measurement}

Figure 1 depicts the tensile strength degradation over time of two plastics (PP and PET). The decrease in tensile strength in PET is far greater than the rate of decrease in tensile strength of PP. The density of PET is higher $\left(1.37 \mathrm{~kg} / \mathrm{m}^{3}\right)$ than PP density $\left(0.94 \mathrm{~kg} / \mathrm{m}^{3}\right)$, which leads to higher tensile strength value.

The tensile strength of both plastic during interaction with Spirulina $s p$ for 112 days showed a greater rate of tensile strength decrease of PET compared to PP. The hydrophilic and hydrophobic nature of polymers plays a role in biofilm and hetero-aggregation formations in the biodegradation process of polymers in the aquatic system (Merina, 2014; Cerca et al., 2005; Lobelle et al., 2011). The formation of biofilms by microorganisms can improve the hydrophilic properties of the plastic surface (Lobelle et al., 2011). PET is more hydrophilic than PP, as it contains polar group ( $\mathrm{C}=\mathrm{O}$ bond) (Lai et al., 2006). Therefore, PET has greater potency to experience exopolysaccharide (EPS) heteroaggregation produced by Spirulina $s p$. Spirulina $s p$ has both hydrophilic and hydrophobic properties because of its high protein contents (Bashir et al., 2015). The exopolysaccharide heteroaggregation that occurs in PET surfaces happened when microalgae reach the stationary growth phase (Long et al., 2017) where (EPS). Heteroaggregation is very important in determining the fate, transportation, transformation and toxicity of nanoparticles in aqua phase (Wang et al., 2015). Heteroaggregation in PET results in more brittle PET which causes the tensile strength of PET decrease faster than in PP.

The difference in the decrease rate of tensile strength in PET and PP can also be caused 


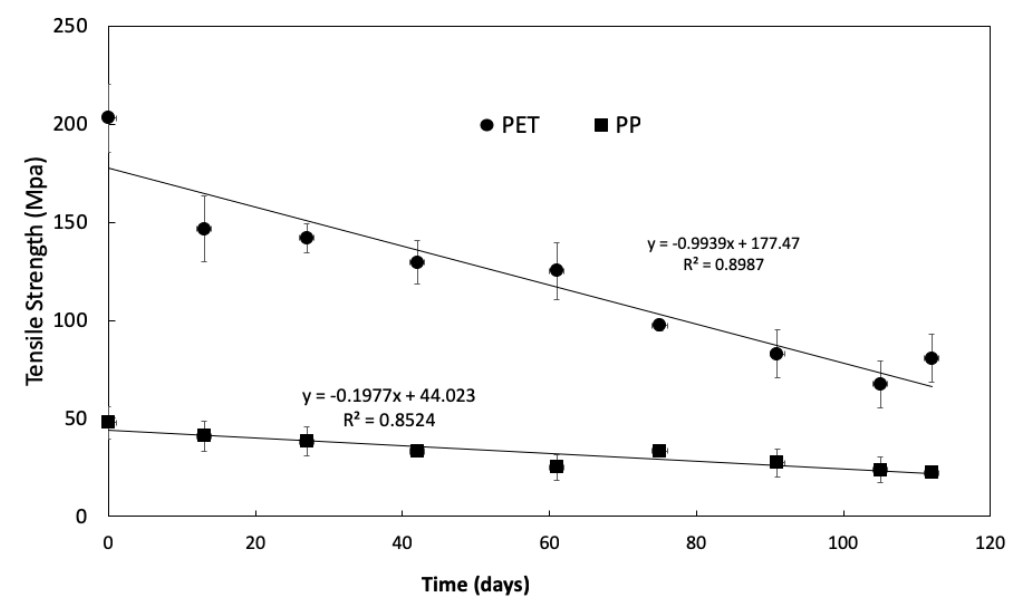

Fig. 1. The changes of tensile strength of polyethylene terephthalate and polypropylene upon degradation time under Spirulina sp influences

by chemical composition, especially the amount of additives added in the process of plastics production (Lagarde et al., 2016).

\section{The change of organic groups investigation by FTIR Analysis}

FTIR analysis is a suitable technique for investigating the degradation of plastics in the environment through the determination of changes in various functional groups that contribute to the plastic polymer compound (Loakeimidis et al., 2016). Some results of research on the FTIR's ability in analyzing organic functional groups in plastic polymers were reported in a review of Jung et al., (2018) who concluded that FTIR spectroscopy is able to provide a simple, effective and non-destructive method for identifying and distinguishing functional groups organics widely in most plastic polymers with high accuracy results.

Figure 2 shows the FTIR analysis of PET before and after interaction with Spirulina $s p$. The characteristic of PET were identified by its functional groups of for $\mathrm{C}=\mathrm{O}$ stretch (ketone) at wavelength of $1718 \mathrm{~cm}^{-1}, \mathrm{C}=\mathrm{C}$ aromatics at $1505 \mathrm{~cm}^{-1}$, $1523 \mathrm{~cm}^{-1}, 1578 \mathrm{~cm}^{-1}$ and $1613 \mathrm{~cm}^{-1}$, (CO) aliphatic ether at $1125 \mathrm{~cm}^{-1}$, aromatics $(\mathrm{CH})$ at $874.5 \mathrm{~cm}^{-1}$ and aromatic bonds $(\mathrm{CH})$ at $733 \mathrm{~cm}^{-1}$.

The spectrum of PET after interaction with Spirulina $s p$ is characterized by the decreasing the peak intensities of the band located at 1613-1505 $\mathrm{cm}^{-1}$ (aromatic $\mathrm{C}=\mathrm{C}$ ) (Fig. 2). It also shows there is no progressive reduction in the relative intensity of the peak carbonyl and the appearance of new absorption bands was observed.

Figure 3 shows the FTIR-ATR spectrogram of the PP surface layer before and after interaction with Spirulina sp. Before the interaction with Spirulina $s p$, the results of the PP spectrogram control gave an important peak in the wavelength region of 3100-3700 $\mathrm{cm}^{-1}$ (water OH stretch, $1456 \mathrm{~cm}^{-1}$ $\left(\mathrm{CH}_{2}\right.$ bend), $1377 \mathrm{~cm}^{-1}\left(\mathrm{CH}_{3}\right.$ bend $), 1166 \mathrm{~cm}^{-1}(\mathrm{CH}$ bend, $\mathrm{CH}_{3}$ rock, $\mathrm{CC}$ stretch), $997 \mathrm{~cm}^{-1}\left(\mathrm{CH}_{3}\right.$ rock, $\mathrm{CH}_{3}$ bend, $\mathrm{CH}$ bend), $840 \mathrm{~cm}^{-1}\left(\mathrm{CH}_{2}\right.$ rock, $\mathrm{C}-\mathrm{CH}_{3}$ stretch), $809 \mathrm{~cm}^{-1}\left(\mathrm{CH}_{2}\right.$ rock, $\mathrm{CC}$ stretch). After interaction with Spirulina sp, the appearance of absorption bands located at 1599 and $1534 \mathrm{~cm}^{-1}$ corresponds to Amide $(\mathrm{C}=\mathrm{O})$ and very strong peak at $1731,48 \mathrm{~cm}^{-1}$ that corresponds to an ester and keton $(\mathrm{C}=\mathrm{O})$. Domagala (2012) found a new absorption band within the wave number range of (1730-1680) $\mathrm{cm}^{-1}$ that corresponds to a carbonyl group as a results of the nucleophilic substitution of PP.

Moreover, the absorption band of carbonyl group in the PP spectrum is broad which indicates the presence of carbonyl group in various products of oxidation such as aldehydes and ketons (Carlsson and Wiles 1969). Figure 3 also shows the new peak at $3343 \mathrm{~cm}^{-1}$, which reveals the presence of Spirulina $s p$ as it was also reported by Theivandran et al., (2015). The results of FTIR-ATR Spectrogram of PP after interaction with Spiruli$n a$ indicate a particular activity of oxidative degradation process of PP in Spirulina sp medium.

\section{Morphological evaluation of microplastics using SEM/EDX Analysis}

The SEM analysis was conducted to investigate the changes in the surface morphology of the plastics. Nauendorf et al., (2016) proved in his study that biofilm formation in surface of plastic depends on several factors such as 


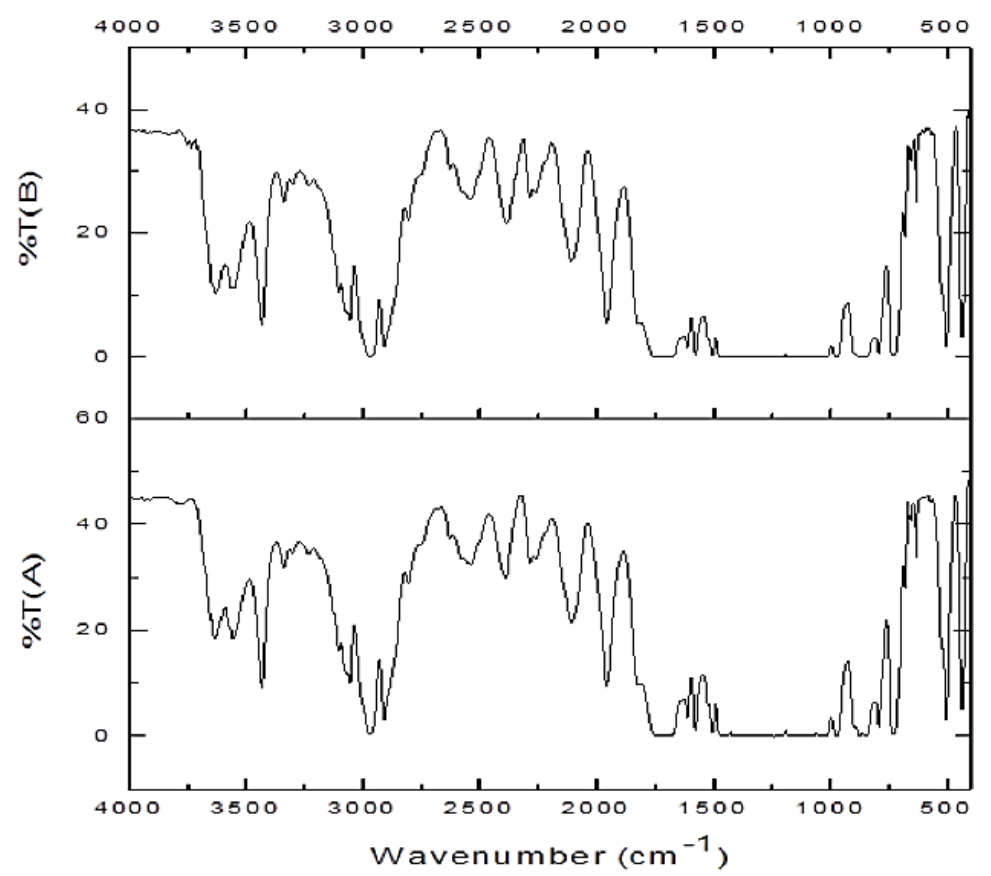

Fig. 2. The FTIR comparative spectra of the PET : (a) before treatment and (b) after treatment with Spirulina sp.

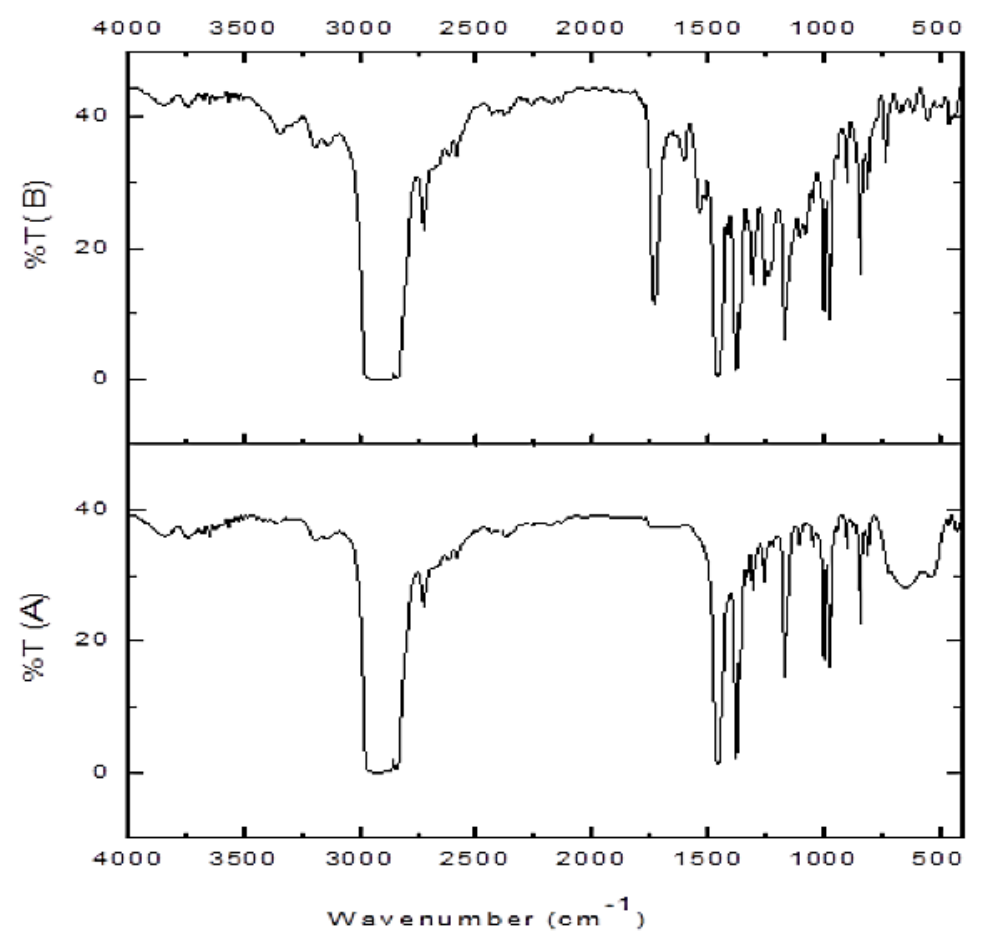

Fig. 3. FTIR comparative spectra of the PP: (a) before treatment and (b) after treatment with Spirulina sp.

plastic surface roughness, plastic hydrophilic surface properties, the properties of substratum and also the bulk liquid properties as well as on cell surface properties. Figure 4 shows the SEM micrographs of the PET and PP surfaces before and after 112 days of interaction with Spirulina sp. Before interaction with Spirulina $s p$ (Fig. 4a) the PET samples had a smooth area among the blisters and (Fig. 4c) the PP samples had a coarser and more textured surface with defects. However, after incubation with the Spirulina $s p$, surface erosion and the formation of pits and cavities on the surface of the samples were observed (Figs. $4 \mathrm{~b}$ and $4 \mathrm{~d}$ ). The 
presence of pits and cavities may be because of the absence of biofilm that become the areas colonized by microorganism, also suggesting that the fungus penetrated into the PET and PP matrix and a bacterial biofilm formed on the surface of plastics. Nakkabi et al.(2015) found that Bacillus subtilis strain has an effect on the change of PET surface morphological heterogenecity and signs of erosion which show the ability to degrade the PET.

This experiment revealed that PET and PP also contribute a carbon source for Spirulina sp to form carbon dioxide as one of the major metabolic end products under aerobic conditions (Shah et al., 2008). In ISO 14852, it was depicted that the identified ultimate aerobic biodegradability of plastic materials in an aqueous medium can be performed by analysing the evolved $\mathrm{CO}_{2}$ and this can be used as a reference in considering the amount of carbon from EDX investigation on PET and PP before and after interacting with microalgae.

Table 1 shows a decrease in carbon concentration by $48.61 \%$ in PET while in PP there is a carbon decline of $36.7 \%$. The plastics that contain chemical compounds in the manufacturing process also have the ability to release and distribute contaminants to the environment as well as contaminate the environment by harmful chemical pollutants, and are able to absorb contaminants from the environment (Teuten et al., 2009). Rummel et al., (2017) reported the occurrence of chemical pollutants transport through the biofilms formed on the surface of the plastic. This is evident from the results of EDX that after plastic treatment with Spirulina $s p$, several inorganic elements were newly identified in plastics. These inorganic elements can be derived from the nutrients added to Spirulina $s p$ media and from the release of additive compounds from the plastic which are added during the process of making plastic itself.

\section{The impact of microplastics on the Spirulina sp growth}

\section{Optical density measurement for Spirulina sp growth}

In this part of the experiment, we characterized the impact of PET and PP microplastics to Spirulina $s p$ growth by measuring the optical density of Spirulina $s p$ in various concentrations of microplastics (Fig. 5).

The decreasing microalgae growth is statistically significant (Fig. 6) among PET, PP and control during 7 days cultivation. Lagarde et al. (2016) found the decreasing microalgae growth after $78 \mathrm{hrs}$ contact and Besseling et al., (2016) resulted in the decrease of microalgae growth

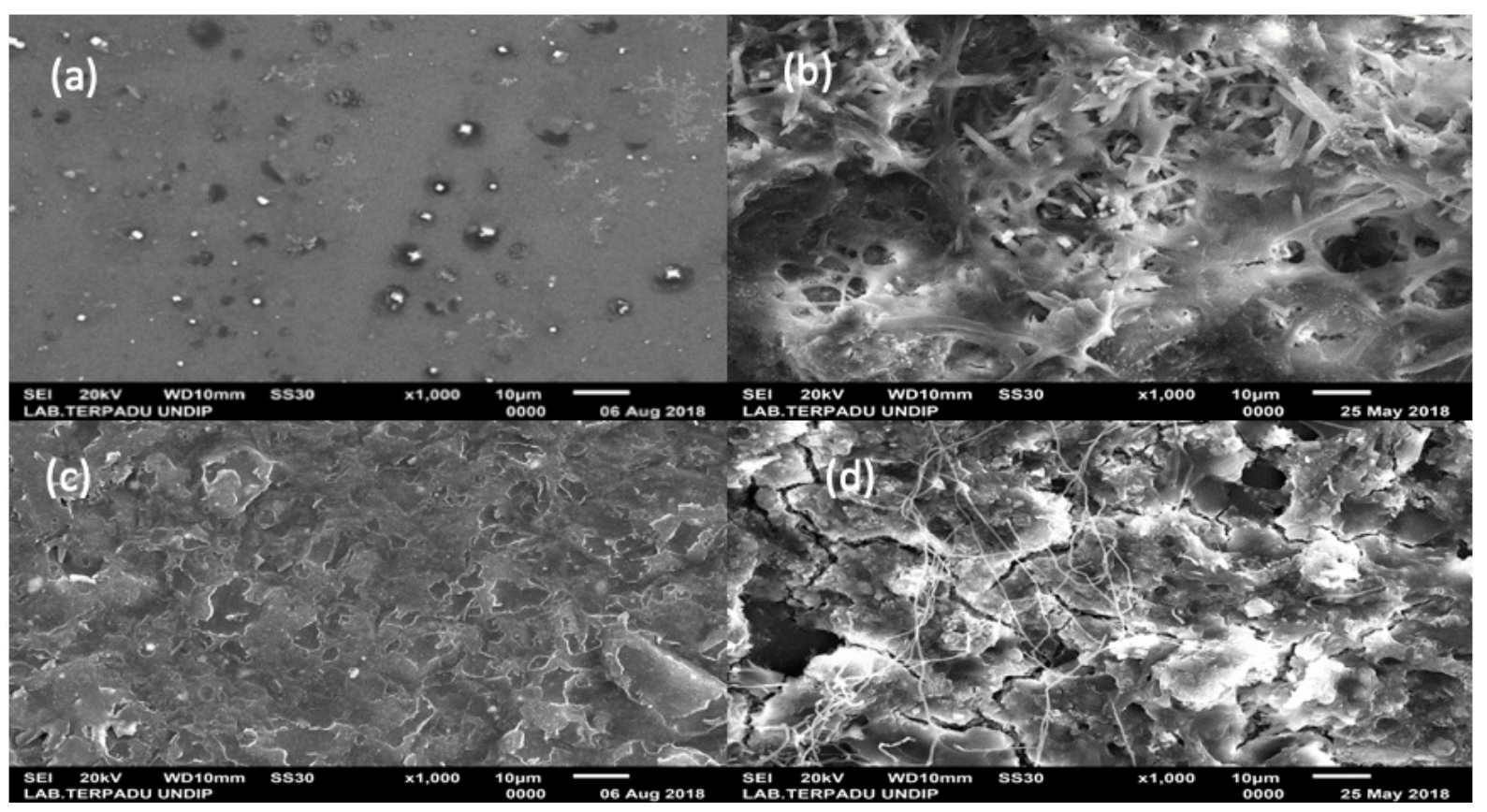

Fig. 4. Morphological analysis using SEM in magnification x 1000 visualizations of the surface topography and roughness of the (a)PET without treatment, (b) PET after treatment with Spirulina sp, (c) PP without treatment, (d)PP after treatment with Spirulina sp for about 112 days. 
Table 1. The EDX result for PET and PP before and after treatment with Spirulina sp

\begin{tabular}{|l|c|c|c|c|}
\hline \multirow{2}{*}{ Compound } & \multicolumn{2}{c|}{ PET } & \multicolumn{2}{c|}{ PPter(\%w) } \\
\cline { 2 - 5 } & Before (\%) & After(\%w) & Before (\%) & 60.59 \\
\hline Carbon, C & 98.98 & 50.86 & 95.72 & 17.74 \\
\hline Nitrogen, N & & 13.69 & & 2.57 \\
\hline Sodium Oxide, Na2O & 0.250 & 0.67 & & 1.07 \\
\hline Magnesium Oxide, MgO & & 1.74 & & 4.86 \\
\hline Alumnia, Al2O3 & & 9.01 & & 3.31 \\
\hline Silica oxide, SiO2 & & 7.26 & & 1.28 \\
\hline Phsosphor petaoxide, P2O5 & & 0.86 & & 1.99 \\
\hline Sulfide, SO3 & & 1.08 & & 0.34 \\
\hline Chloride, Cl & & 0.22 & & 0.4 \\
\hline Potasium Oxide, $\mathrm{K2O}$ & & 10.8 & 0.23 & 5.04 \\
\hline Calcium Oxide, CaO & 1.25 & 0.45 & 0.81 \\
\hline Copper(II) Oxide, CuO & & 1.01 & 3.6 & \\
\hline Zinc Oxide, ZnO & & 1.06 & & \\
\hline Zirconium Dioxide, ZrO2 & & & \\
\hline
\end{tabular}
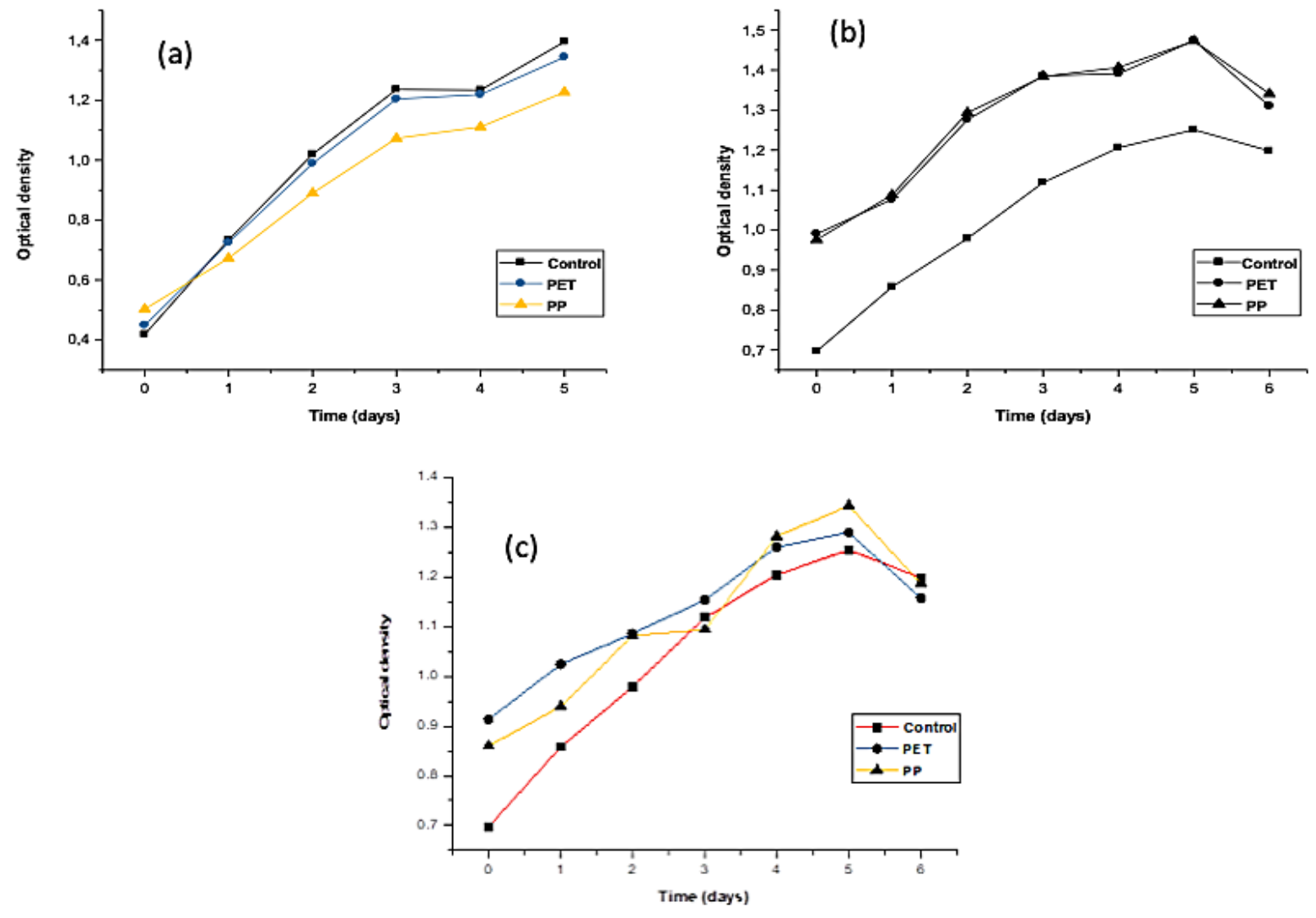

Fig. 5. The growth of microalgae Spirulina $s p$ culture in medium with variation of microplastic concentration(a) $150 \mathrm{mg} / 500 \mathrm{~mL}$, (b) $250 \mathrm{mg} / 500 \mathrm{~mL}$ and (c) $275 \mathrm{mg} / 500 \mathrm{~mL}$

after 72 hours in the presence of $250 \mathrm{~g} / \mathrm{L}$ of polystyrene. However, exposing different microplastics concentrations level gives different microalgae growth rates whereas the higher microplastics concentration in the microalgae led to lowering the growth rate of the microalgae. Microalgae with the addition of PET and
PP (Figure 8), generally have lower growth rate constant as compared to the microalgae without microplastic addition $\left(0.399\right.$ day $\left.^{-1}\right)$. This is because of the presence of microplastics in Spirulina $s p$ culture may cause shading effects and lead to the inhibition of light intensity which is important in the process of microalgae 


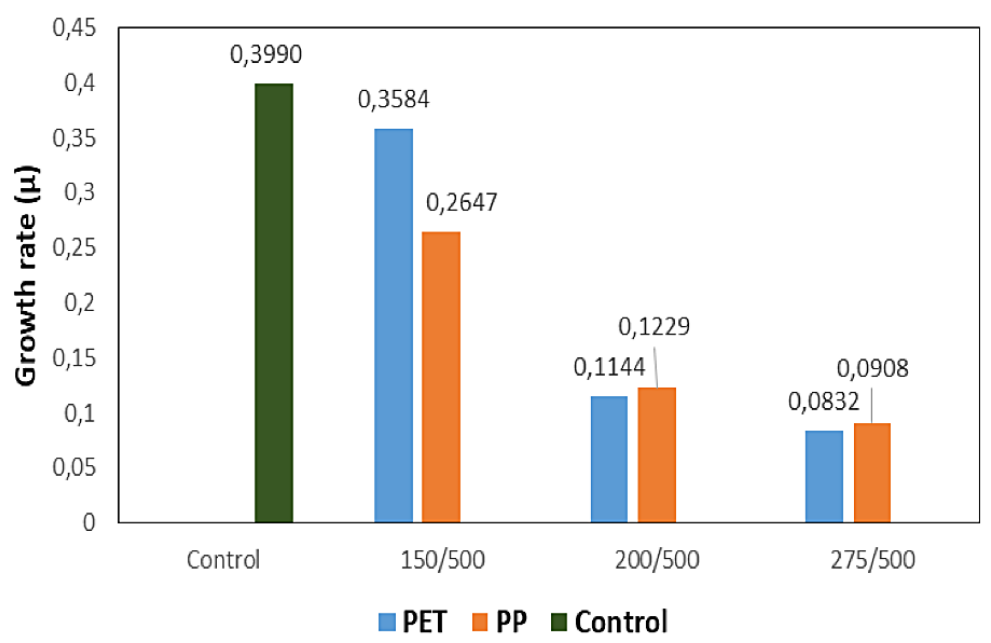

Fig. 6. Comparison of effect of microplastics in various concentrations to Spirulina sp growth rate $(\mu)$

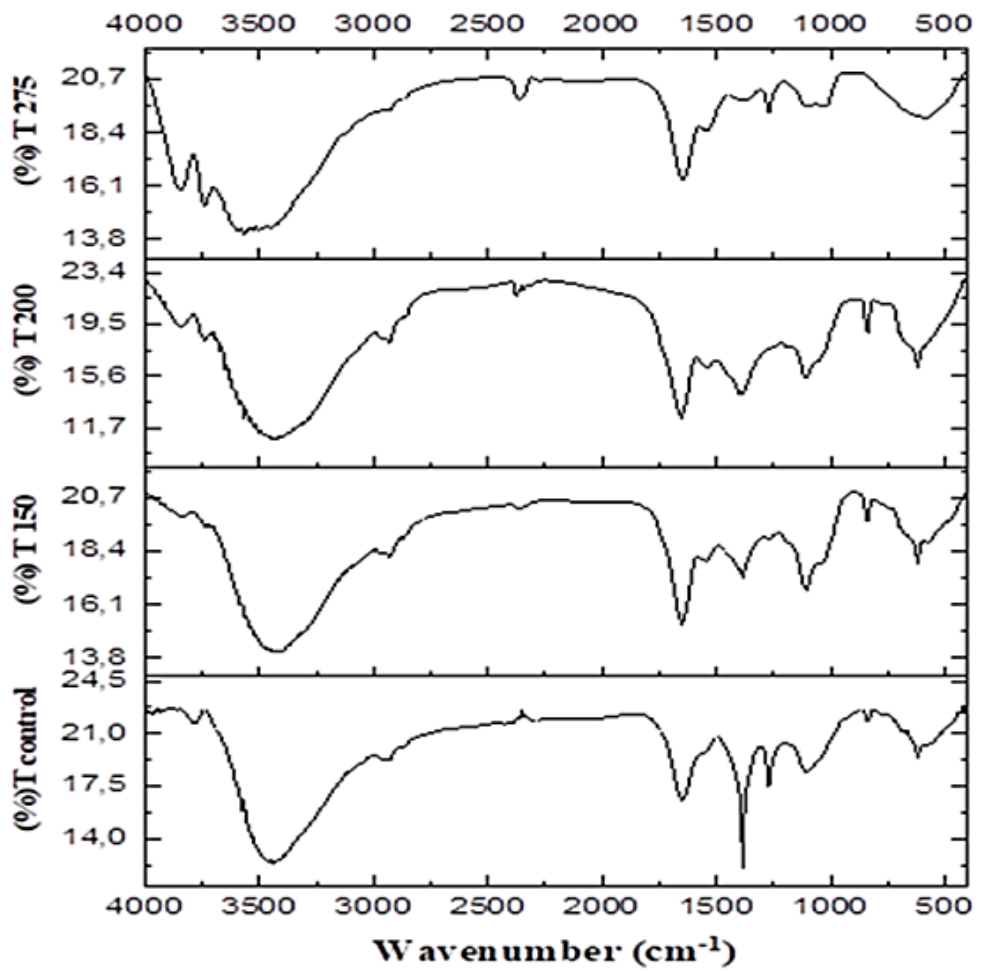

Fig. 7. FTIR comparative of spectra of Spirulina sp under micro plastic Polyethylene Terephthalate influence in various concentrations.

photosynthesis (Hadiyanto et al., 2012). The microplastics dosage applied with a concentration of $150 \mathrm{mg} / \mathrm{mL}$ results in higher microalgae growth rates in PET $\left(0.3584\right.$ day $\left.^{-1}\right)$ compared to PP $\left(0.2647\right.$ day $\left.^{-1}\right)$ whereas at higher concentrations of $200 \mathrm{mg} / \mathrm{mL}$ and $275 \mathrm{mg} / \mathrm{mL}$ the opposite results were found in which the microalgae with the addition of PP microplastics (0.1229 day $^{-1}$ and 0.907 day $^{-1}$ ) have a higher growth rate than the microalgae with the addition of PET microplastics $\left(0.1144\right.$ day $^{-1}$ and 0.0832 day $\left.^{-1}\right)$.

\section{FTIR analysis}

The FTIR analysis of Spirulina $s p$ in fresh water without any treatment (Fig.7 and Fig. 8), represent the following associated functional groups: at the wavelength of $3572 \mathrm{~cm}^{-1}$ representing the $\mathrm{O}-\mathrm{H}$ stretching vibration and thus presence of alcohols and phenols. The peak at $3436 \mathrm{~cm}^{-1}$ represents the strong $\mathrm{N}-\mathrm{H}$ (amine) and then at 1651 indicates $-\mathrm{C}=\mathrm{C}$ - stretching vibration presence of alkenes, and peak of $1271 \mathrm{~cm}^{-1}$ presence of $\mathrm{C}-\mathrm{H}$ wag $\left(-\mathrm{CH}_{2} \mathrm{X}\right)$ stretching of alkyl 


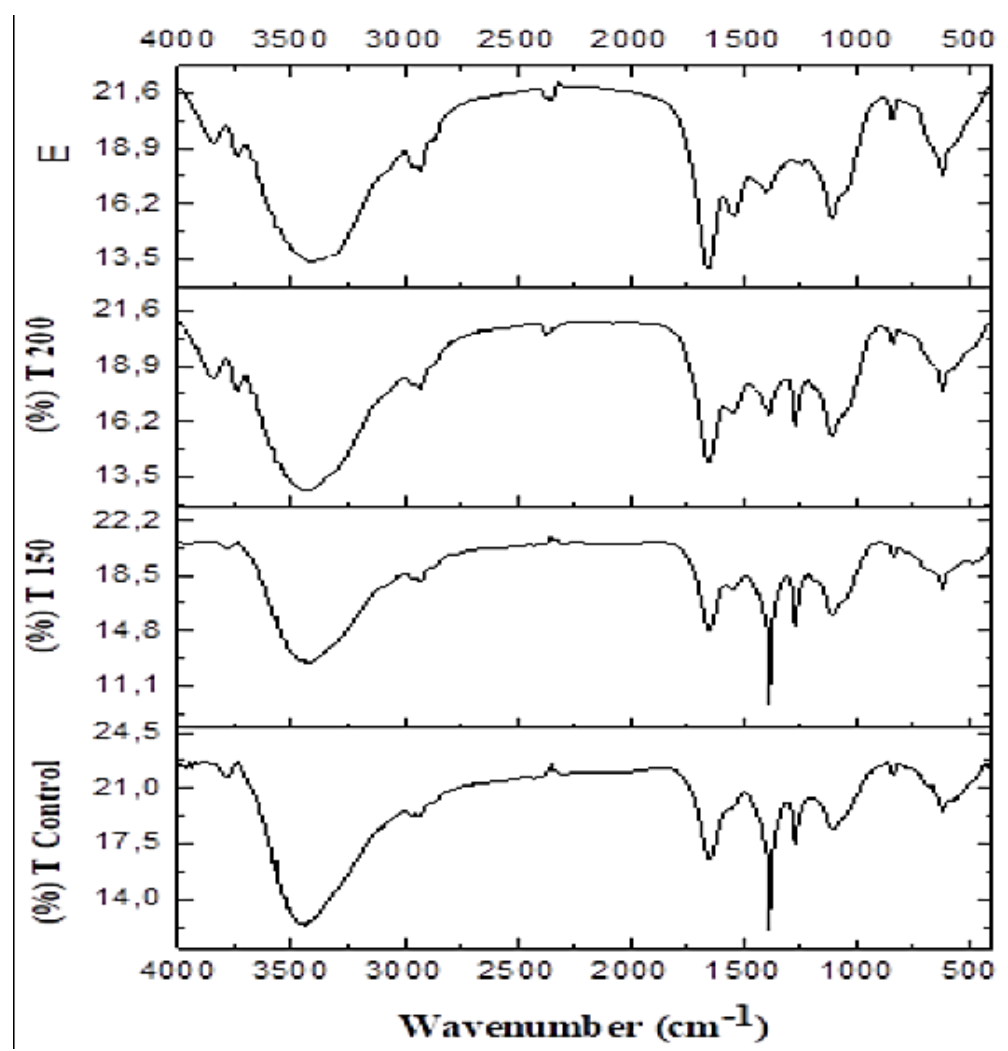

Fig. 8. FTIR comparative of spectra of Spirulina sp under micro plastic Polypropylene influence in various concentrations.

halides. Furthermore, the frequency ranges of $1200-1020 \mathrm{~cm}^{-1}$ is the presence of C-OH stretching and peak of $838 \mathrm{~cm}^{-1}$ present N-H symmetric stretching vibration primary of secondary amines. The last peak at $618 \mathrm{~cm}^{-1}$ representing $\mathrm{C}-\mathrm{Br}$ stretching vibration indicates the presence of alkyl halides compounds.

Some new peaks emerge and change of their intensity after additions of microplastics in Spirulina $s p$ culture. The appearance of the absorption spectra in the region of $2300-2400 \mathrm{~cm}^{-1}$ only occurs in PET under microplastics treatment. The highest concentration of PET was shown by the higher intensity of the spectra in that region (from $150 \mathrm{mg} / 500 \mathrm{~mL}$ to $275 \mathrm{mg} / 500 \mathrm{~mL}$ ), and this is slightly different to the PP application. The appearance of spectra in the $2300-2400 \mathrm{~cm}^{-1}$ region only occurs in Spirulina $s p$ by applying $200 \mathrm{mg} / 500 \mathrm{~mL}$ and $275 \mathrm{mg} / 500 \mathrm{~mL}$ of microplastics. Gerakines et al. (1995) reported the appearance spectra at peak $2343 \mathrm{~cm}^{-1}$, which was identified as the existence of $\mathrm{CO}_{2}$. The fact that higher $\mathrm{CO}_{2}$ intensity in Spirulina $s p$ added by PET and PP is related to the availability of carbon supplied by microplastic which lead high amount to be converted to $\mathrm{CO}_{2}$. This conversion process is part of the mineralization in the biodegradation process. Gupta et al. (2007) explained that the mineralization process in plastic biodegradation will occur in fragmented plastics where the microplastic residues produced are carbon as food sources and the converted energy produces $\mathrm{CO}_{2}$. Furthermore, Shah et al., (2008) reported that under aerobic conditions oxygen was used by microbes to oxidize carbon to produce $\mathrm{CO}_{2}$ as a major metabolic end product and this is also supported by the research of Hoffmann et al. (1997) and Lucas et al. (2008). Arutchelvi et al. (2008) and Rummel et al. (2017) explained that biomass accumulation characterized by the growth of microorganisms was capable to utilize polymers as a carbon sources and this cause the main chain cleaves that leading the formation of low molecular weight compounds as impact of the extra cellular enzymes secreted by the microorganism, called as bio-fragmentation. This step is followed by diffusing oligomers into the microorganism to obtain assimilation. When the biodegradation is accomplished, it will produce $\mathrm{CO}_{2}, \mathrm{H}_{2} \mathrm{O}$ and biomass under aerobic conditions.

The decrease of intensity in some peaks and the emergence of new peaks after application of 
PET and PP in Spirulina sp is an indication of the interaction between microplastics and Spirulina $s p$. The appearance of FTIR absorption peak in the region of 3700-3800 $\mathrm{cm}^{-1}$ in Spirulina sp under addition of both microplastics is in line with the increasing microplastics dosage applied. The absorption is due to $\mathrm{O}-\mathrm{H}$ stretching modes in the range of 3800-3000 $\mathrm{cm}^{-1}$. The IR spectra can be represented as a sum of contributions from interfacial and bulk like water (Profio et al., 1998)

\section{CONCLUSION}

In this study, the measurements of tensile strength, analysis with FTIR-ATR and SEM-EDX were carried out on PET and PP after interacting with Spirulina $s p$ for 112 days to understand the biodegradation process in PET and PP. From the measurement results of tensile strength, PET appears to provide a greater decrease in tensile strength compared to PP, but the opposite condition occurs in FTIR-ATR analysis, which shows a more significant change in functional groups in PP compared to PET. Furthermore, both PET and PP surface imaging with SEM after interaction with Spirulina $s p$ in 112 days showed signs of surface alteration. Although the signs of biodegradation in PET and PP are indicated by the results of the analysis, but it still cannot be concluded that the process of biodegradation with microalgae provides the most effective results. Further research is required to obtain more infromation on the effectivity of microalgae Spirulina $s p$ on its involved in biodegradation processes. Another study of PET plastic and PP impact to Spirulina $s p$ growth shows a strong influence of PET and PP on the growth of Spirulina sp. The interaction between plastic and microalgae provides phenomena that need to be further studied to devise a solution in handling the abundance of plastic waste in the aquatic system and maintaining the survival of organisms in waters.

\section{Acknowledgements}

This research was conducted and generously supported by C- Biore research Group at UPT laboratorium Diponegoro University, Semarang, central Java - Indonesia and as a prerequisite for accomplish my doctoral program in Environmental Science Doctoral Departement, the graduate school of Diponegoro University.

\section{REFERENCES}

1. Alshehrei, F., 2017, Biodegradation of synthetic and natural plastic by microorganisms, Journal of Applied \& Environmental Microbiology, 5(1), 8-19.

2. Alvarez-Zeferino, J.C., Beltran-Villavicencio, M., Vazquez-Morillas, A., 2015, Degradation of plastics in seawater in laboratory, Open Journal of Polymer Chemistry, 5, 55-62.

3. Andrady, A.L., 2003, Plastics in the environment. In: Andrady, A.L. (Ed.), Plastic in the environment. John Wiley \& Sons, New jersey, NJ, p. 762.

4. Andrady, A.L. and Neal, M.A., 2009, Applications and Societal benefits of Plastics, Phil.Trans R.Soc.B, 364, 1977-1984.

5. Arkatkar, A., Arutchelvi, J., Sudhakar, M., Bhaduri, S., Uppara, P.V., Doble, M., 2009, Approaches to enhance the biodegradation of polyolefins, The open Environmental Engiineering Journal, 2, 68-80.

6. Arutchelvi, J., Sudhakar, M., Arkatkar, A., Doble, M., Bhaduri, S., Uppara, V.P., 2008, Biodegradation of polyethylene and polypropylene, Indian Journal of Biotechnology, 7, 9-22.

7. Auta, H.S., Emike, C., Barasarathi, J., Fauziah, S.H., 2017, Growth kinetics and biodeterioration of polypropylene microplastics by Bacillus sp and Rhodococcus sp, Marine Pollution Bulletin, 127, 15-21.

8. Bashir, S., Sharif, M.K., Butt, M.S., Shahid, M., 2016, Functional properties and amino acid profile of Spirulina plantesis protein isolates, Paj.j.Sci.ind. Ser.B:biol.sci, 59 (1), 12-19

9. Bertin, D., Leblanc, M., Marque, R.A., Sylvain., Siri, D., 2010, Polypropylene degradation:theoretical and experimental investigations. Polymer degradation and stability 95, PP 782-791

10. Carina Longo, Michele Savaris, Mara Zeni, Rosmary Nichele Brandalise, Ana Maria Coulon Grisa, 2011, Degradation study of polypropylene (PP) and bioriented polypropylene (BOPP) in the environment, Mat. Res. Vol. 4.

11. Carlsson D.J., Wiles, D.M., 1969, The Photodegradation of polypropylene films. II. photolysis of ketonic oxidation products, Macromolecules, 2, 587.

12. Cerca, N., Pier, G.B., Vilanova, M., Oliveira, R., Azeredo, J., 2005, Quantitative analysis of adhesion and biofilm formation on hydrophilic and hydrophobic surface of clinical isolates of Staphylococcus Epidermidis, Research in Microbiology, 156, 506-514.

13. Cole, M., Lindeque, P., Halsband, C., Galloway, T.S., 2011. Microplastics as contaminants, ILSI Europe Reports Series by Philip Tice, 2002, Packaging materials:3.Polypropylene as a packaging material for foods and beverages. ILSI Press. 
14. CWC Best Practices in PET Recycling: Drying methods and requirements, 1997. [Online]. Available: http://infohouse.p2ric.org/ref/13/12488.pdf

15. Das, P.M., Kumar, S., 2013, Influence of Cell Surface Hydrophobicity in colonization and biofilm formation on LDPE biodegradation, Int.Journal of Pharmacy and Pharmaceutical Sciences, Vol.5, Issue 4

16. Derraik, J.G.B., 2002. The Pollution of the marine environment by plastic debris; a review.Marinne Pollution Bulletine. 44, 842-852.

17. Domagala, W.U., 2012, The Use of the spectrometric technique FTIR-ATR to examine the polymerssurface, INTECH, Chapter 3, 85-104.

18. Eriksen, M., Mason, S., Wilson, S., Box, C., Zellers, A., Edwards, W, 2013, Microplastic pollution in the surface waters of the Laurentian Great Lakes. Marine Pollution Bulletin 77, 177-182.

19. Farzi, A., Dehnad, A. And Fotouhi, A.F., 2019, Biodegradation of polyethylene terephthalate waste using streptomyces species and kinetic modeling of the process, biocatalysis and agricultural biotechnology, 17, 25-31

20. Gewert, B., Plassmann, M.M., MacLeod, M., 2015, Pathways for degradation of Plastic Polymers Floating in the Marine Environment, Env. Science:Processes and Impacts 17(9).

21. Guo, M., Chu, Z., Yao, J., Feng, W., Wang, Y., Wang, L., Fan, Y., 2016., The Effects of Tensile Stress on Degradation of Biodegradable PLGA membranes:A quantittative study, Polymer Degradation and Stability, 124, 95-100.

22. Habib M., Ahsan B., Parvin Mashuda, 2008. A review on culture, production and use of spirulina as food for humans and feeds for domestic animals and fish. FAO Fisheries and Aquaculture Circular No. 1034.

23. Hadiyanto and Maulana Adzim, 2012. Mikroalga: Sumber pangan dan energi masa depan. Undip Press.

24. Hadiyanto, Widayat, Kumoro C.A., 2012. Potency of microalgae as biodiesel source in Indonesia. International journal of renewable energy development. 1(1).

25. Hariyati, R. 2008. Pertumbuhan dan biomassa spirulina sp dalam skala laboratoris. BIOMA, 10(1), 19-22.

26. Howe, D.V., 1999, Polymer Data Handbook. Oxford University Press, 780-785.

27. Hoffmann, A., Kreuzberger, S., Hinrichsen, G., 1994, Influence of Thermal Degradation on Tensile Strength and Young"s Modulus of Poly(hydroxybuyrate), Polymer Bulletin, 33, 355-359.

28. Jambeck J.R, Geyer R, Wilcox C, Seigler T.R., Perryman M., Andrady A., Narayan R., Lavender Law $\mathrm{K}, 2015$, Plastic waste inputs from land into the ocean, Sciencemag.org, 347(6223), 768-771.
29. Jung, M.R., Horgen, F.D., Orski, S.V., C Rodriguez, V., Beers, K.L., Balazs, G.H., Jones, T.T., Work, T.M., Brignac, K.C., Royer, S.J., Hyrenbach, K.D., Jensen, B.A., Lynch, J.M., 2018, Validation of ATR FT-IR to identify Polymer of Plastic Marine debris, including those ingested by Marine Organisms, Marine Pollution Bulletin, 127, 704-716.

30. Lagarde, F., Olivier, O., Zanella, M., Daniel, P., Hiard, S., Caruso, A., 2016, Microplastic interactions with freshwater microalgae:Heteroaggregation and changes in plastic density appear strongly dependent on polymer type, Environmental Pollution, 215, 331-339.

31. Lai, J., Sunderland, B., Xue, J., Yan, S., Zhao, W., Folkard, M., Michael, B.D., Wang, Y., 2006, Study on Hydrophilicity of Polymer surfaces improved by Plasma treatment, Applied Surface Science, $252,3375-3379$.

32. Lee, K.-W., Shim, W.J., Kwon, O.Y., Kang, J.-H., 2013. Size-dependent effects of micro polystyrene particles in the marine copepod Tigriopus japonicus. Environ. Sci. Technol. 47, 11278e11283.

33. Loakeimidis, C., Fotopoulou, K.N., Karapanagioti, H.K., Geraga, M., Zeri, C., Papathanassiou, E., Galgani, F., Papatheodorou, G., 2016, The Degradation Potential of PET Bottles in the Marine Environment:An ATR-FTIR Based Approach, Scientific Reports, 6:23501.

34. Lobelle, D. And Cunliffe, M., 2011, Early Microbial Biofilm Formation on Marine Plastic Debris, Marine Pollution Bulletin, 62, 197-200.

35. Long, M., Moriceau, B., Gallinari, M., Lambert, C., Huvet, A., Raffray, J., Soudant, P., 2015, Interactions between Microplastics and Phytoplankton Aggregates:Impact on their respective Fates, Marine Chemistry, 175, 39-46.

36. Long, M., Paul-Pont, I., Hegaret, H., Moriceau, B., Lambert, C., Huvet, A., Soudant, P. 2017, Interaction between polystyrene microplastics and marine phytoplankton lead to species-specific hetero-aggregation. Environmental Pollution, 228, 454-463.

37. Lucas .N, Bienaime. C, Belloy. C, Queneudec.M, Silvestre. F, Edmundo. J, Saucedo.N, 2008.Polymer biodegradation: Mechanisms and estimation techniques. Chemosphere.73, 429-442.

38. Ma, T., Bhushan, B., 2003, Mechanical, Hygroscopic and Thermal Properties of Ultrathin Polymeric Substrates for Magnetic Tapes, J.of Applied Polymer Science, 89(2), 3052-3080.

39. Maddah, H.A., 2016, Polypropylene as a promising plastic: A review, American Journal of Polymer Science, 6(1), 1-11.

40. Moore, C.J., 2008. Synthetic polymers in the marine environment: a rapidly increasing. Long-term threat. Environ. Res.108, 131-139.

41. Mortula M.M., 2013. Health Risk Assessment of PET Bottles in GCC, International journal of Environmen- 
tal and Ecological Engineering, 7(3), 141-146.

42. Muthukumar, A. and Veerappapillai, S., 2015, Biodegradation of plastics-A brief review, Int. J. Pharm. Sci. Rev. Res., 31(2), Article No. 36, 204-209.

43. Nakkabi, A., Elmoualij, N., Sadiki, M., Koraichi, S.I., Fahim, M., 2015. Biodegradation of Poly(Ethylenen Terephthalate) bu Bacillus Subtilis, Int.Journal of Recent Advances in Multidisciplinary Researc, 2(2), 1060-1062.

44. Nauendorf, A., Krause, S., Bigalke, N.K., Gorb, E.V., Gorb, S.N., Haeckel, M., Wahl, M., Treude, T., 2016, Microbial Colonization and Degradation of Polyethylenen and Biodegradable Plastic Bags in Temperate Fine-Grained Organic -Rich Marine Sediments, Marine Pollution Bulletin, 103, 168-178.

45. Nowak, B., Pajak, J., Labuzek, S., Rymarz, G., Talik, E., 2011, Biodegradation of Poly(ethylene tererphthalate) modified with Polyester "Bionolle" by penicillium Funiculosum, Polimery, 56(1), 35-44.

46. Patchanee Chammingkwan, Fumitaka Yamaguchi, Minoru Terano, Toshiaki Taniike, 2017, Influence of isotacticity and its distribution on degradation behaviour os polypropylene, Polymer degradation and stability, 143, 253-258.

47. Profio, P.D., Germani, R., Onori, G., Santucci, A., Savelli, G., Bunton, C.A., 1998, Langmuir, 14(4), 768-772.

48. Rezania, S., Park, J., Din, M.F.M., Taib, S.M., Talaiekhozani, A., Yadav, K.K., Kamyab, H., 2018, Microplastics pollution in different aquatic environments and biota: A review of recent studies. Marine Pollution Bulletin 133, 191-208.

49. Rummel, C.D., Jahnke, A., Gorokhova, E., Kuhnel, D., Jansen, M.S., 2017, Impacts of Biofilm Formation on the Fate and Potential Effects of Microplastic in the Aquatic Environment, Environ. Sci.Technol.Lett., 4(7), 258-267.

50. Schmitt, J., Flemming, H., 1998, FTIR -Spectroscopy in Microbial and Material Analysis, International Biodeterioration \&Biodegradation, 41, 1-11.

51. Schimanski, T., 2002, High-performance polypropylene structures for eco-friendly, fully recycable composites, Technische Universiteit Eindhoven DOI:10.6100/IR555619.

52. Shah, A.A., Hasan, F., Hameed, A., Ahmed, S., 2008, Biological degradation of plastics:A comprehensive review, Biotechnology Advances, 26, 246-265.

53. Sharon, C and Sharon, M., 2012, Studies on Biodegradationof Polyethylenen Terephthalate:Synthetic
Polymer, Journal of Microbiology and Biotechnology Research, 2(2), 248-257.

54. Sjollema .B.Sascha, Redondo-Hasselerharm .P, Leslie.A Heather, Kraak .H.S.Michiel Vethaak .Dick.A, 2015, Do plastic particles affect microalgal photosynthesis and growth?, 15, 30116-30118.

55. Strapasson, R., Amico, S.C., Pereira, M.F.R., Syndenstricker, T.H.D., 2005, Tensile and Impact behavior of Polypropylene/Low density Polyethylene Blends, Polymer Testing, 24, 468-473.

56. Teuten, E.L., Saquing, J.M., Knappe, D.R., Barlaz, M.A., Jonsson, S., Bjorn, A., Rowland, S.J., Thomspson, R.C., Galloway, T.S., Yamashita, R., 2009. Transport and release of chemicals from plastics to the environment and to wildlife. Philos, T. Roy. Soc. B 364 (1526), 2027-2045.

57. Theivandran, G., Ibrahim, S.M., Murugan, M., 2015, Fourier Transform Infrared (FT-IR) Spectroscopic Analysis of Spirulina Fusiformis, Journal of Medicinal Plants Studies, 3(4), 30-32.

58. Thompson, R.C., Olsen, Y., Mitchell, R.P., Davis, A., Rowland, S.J., John, A.W.G., McGonigle, D., Russell, A.E., 2004. Lost at sea: Where is all the plastic? Science 304, 838.

59. Tuo, H., Lu, Z., Ma, X., 2017, Effects of Environment on Tensile Properties of Laminated Composites Containing a Central Hole, 2nd International Conference on Materials Science, Resource and Environmental Engineering (MSREE), AIP Conf. Proc. 1890, 040101-1-040101-7.

60. Venkatachalam S., Nayak G.S., Labde V.J., Gharal R.P,, Rao K., Kelkar K. Anil, 2012. Degradation and Recyclability of Poly(Ethylene Terephthalate), INTECH Chapter 4.

61. Wang, H., Adeleye, A.S., Huang, Y., Li, F., 2015, Heteroaggregation of nanoparticles with biocolloids and geocolloids, Advances in colloid and interface Science, 226.

62. Wolfgang Fritsche and Martin Hofrichter, 2008, Aerobic degradation by microorganisms, Biotechnology: Environmental Processes II, Vol. 11, Second Edition. Chapter 6, 147-155.

63. Yoshida, S., Hiraga, K., Takehana, T., Taniguchi, I., Hironao, Y., Maeda, Y., Toyohara, K., Miyamoto, K., Kimura, Y., Oda, K., 2016, A Bacterium that Degrades and Assimilates Poly(ethylene terephthalate), Science, 351, 1196.

64. Yurtsever M., Kirkan E.O., Sevindik T.O., Tunca H, 2017, The impact of PS Microplastics on green algae Chlorella vulgaris Growth. CEST. 